\title{
Diyet Polikliniğine Başvuran Hastalarda Yeme Bağımlılı̆̆ının Epidemiyolojisinin Araştırılması
}

\author{
F.Ebru ATABAY ${ }^{1}$, Duygu ALTIN ${ }^{2}$, Baykul ALTIN ${ }^{3}$
}

\begin{abstract}
Özet: Son yıllarda literatürde güncel bir kavram olan yeme bağımlılı̆̆ı, diğer yeme bozukluklarından ayrı bir yapı olarak değerlendirilmektedir. Bağımlılıkta sık görülen kullanmak için dayanılmaz istek hissetme, istenilenden daha fazla miktarda tüketme, madde kullanmak için fazla zaman harcama vb. davranışlarla örtüştüğü belirtilmektedir. Bu çalışmada diyet polikliniğine çeşitli sebeplerle başvuran hastalarda yeme bağımlılığının epidemiyolojisinin araştırılması amaçlanmıştır. Çalışmaya basit tesadüfi örneklem yoluyla seçilen, diyet polikliniğine başvuran 101 kişi dahil edilmiştir. Haziran 2019 - Ağustos 2019 tarihleri arasında gerçekleştirilen çalışmada, kişisel bilgi formu ve Yale Yeme Bağımlılı̆̆ ölçeğinden yararlanılmıştır. Araştırma bulguları değerlendirilirken istatistiksel metotlar (frekans, yüzde, ortalama, standart sapma) kullanılmıştır. Katılımcıların \%62,4'ü(n=63) kadın, \%37,6'sı(n=38) erkekti. Yaş ortalaması 51,5( $\pm 14,77)$ idi. Yeme bağımlılı̆ı görülme oranı \%60,4(n=61) olarak norm değer olan \%11,6'nın çok üzerinde bulundu. Bağımlılık multidisipliner bir alan olarak diyet polikliniklerinde de, yalnızca beslenme uzmanlarının değil bağımlılık uzmanlarının da işbirliğinde ele alınmalıdır.
\end{abstract}

Anahtar kelimeler: Yeme Bağımlılı̆̆ı, Diyet, Obezite, Bağımlılık

\section{Epidemiological Research of Food Addiction Within Patients Referred To Diet Policlinic}

\begin{abstract}
In recent years, food addiction, a current subject in the literature, has been evaluated as a seperate concept from other eating disorders. A strong desire for use, consumption more than the desired, spending so much time, which are seen frequently in addiction, are commonalities stated. In this study, the aim is to search the epidemiology of food addiction in patients referred to diet policlinic for several reasons.101 participants that are referred to diet policlinic are included in the study with random sampling method. In the study which was performed between the dates July 2019 -August 2019, personal information form and Yale food addiction scale are applied. When the data was analyzed, statistical methods ( frequency, percentage, average, standard deviation) are used. $62,4 \%(n=63)$ of participants were female, 37,6\%(n=38) were male. Average age was $51,5( \pm 14,77)$. The prevalance of food addiction was $60,4 \%(n=61)$, as it is found to be extremely over the norm value, which was $11,6 \%$. Addiction, as a multidisciplinary field, need to be handled by not only dieticians but also in their collaboration with addiction experts.
\end{abstract}

Keywords: Food Addiction, Diet, Obesity, Addiction

\footnotetext{
${ }^{1}$ Yalova Devlet Hastanesi Diyet Polikliniği Merkez/Yalova

${ }^{2}$ Yalova Denetimli Serbestlik Müdürlüğü Sahil Mah. İnönü Cad. No:56/9 Çiftlikköy/Yalova

${ }^{3}$ Yalova Üniversitesi Sosyal Politika Bölümü Yalova Üniversitesi Sosyal Bilimler Enstitüsü Çınarcık Yolu Yalova

Address of correspondence/ Yazışma adresi: Altın, D., Yalova Devlet Hastanesi Diyet Polikliniği Merkez/Yalova, E-mail: duygu.altin@gmail.com
}

Date of Received/Geliş Tarihi: 19.10.2019, Date of Revision/Düzeltme Tarihi: 02.11.2019, Date of Acceptance/Kabul Tarihi: 06.11.2019

Citing/ Referans Gösterimi: Atabay, F.E., Altın, D., Altın B. (2019). Diyet Polikliniğine Başvuran Hastalarda Yeme Bağımlılı̆̆ının Epidemiyolojisinin Araştırılması. Kıbrıs Türk Psikiyatri ve Psikoloji Dergisi, 1(Özel Sayı.1): 27-29 doi:10.35365/ctjpp.19.special1.7 


\section{Giriş}

Son yıllarda literatürde güncel bir kavram olan yeme bağımlılı̆̆1 yeme davranışı üzerine kontrolün kaybolmasıyla bazı besinlerin giderek artan düzeyde tüketilmesi olarak tanımlanmaktadır (Moreno \& Tandon, 2011). Özellikle obez olan ve aşırı yemek yiyen bireylerde yaygın görülmekle, diğer yeme bozukluklarından ayrı bir yap1 olarak değerlendirilmektedir. Meyilli kişilerdeki kilo artışı, diyette kayma, aşırı yeme davranışlarında yeme bağımlılığının olası rolü hakkında giderek artan bir bilimsel ilgi söz konusudur. Özellikle son 20 yılda hem kamu ilgisinde hem de bilimsel değerlendirmelerde yeme bağımlılı̆̆ konseptinde düzenli bir artış görülmektedir (Davis, 2013; Meule, 2015). Bunun birden çok nedeni olduğu değerlendirilmektedir. Başlıca nedenler arasında obezitenin yaygınlaşması, buna eşlik eden yüksek ödüllendirici, ucuz ve erişilebilir gıdaların (fast food vb.) tüketiminin artışı yer almaktadır. Obezite şu anda önlenebilir ölüm nedenlerinin başında gelmektedir, beklenen yaşam süresinde kısalmasında temel unsurdur ve medikal sistemde yükün artmasına neden olmaktadır (Kelly, Yang, Chen, Reynolds \& He, 2008; Mokdad, Marks, Stroup \& Gerberding, 2004; Ng vd., 2014). Aşırı kilolu olmanın kamu sağlığı sonuçları daha aşikar hale geldikçe, temel bilimler bağımlılık bozuklukları ile aşırı yemek tüketiminin altında yatan biyopsikososyal nedenler arasında ödül, motivasyon, stres, öz denetim ve inhibitör kontrol sistemleri vb. paralellikler bulmuştur (Ahmed, Guillem, \& Vandaele, 2013; Avena, Rada, \& Hoebel, 2008; Johnson \& Kenny, 2010; Parylak, Koob, \& Zorrilla, 2011; Volkow, Wang, Tomasi, \& Baler, 2013). $\mathrm{Bu}$ durum, en azından belirli grup insanlar için bağımlılık süreçlerinin aşırı yeme davranışına neden olduğu hipotezine götürmüştür(Gold, Frost-Pineda, \& Jacobs, 2003; Gold, Graham, Cocores, \& Nixon, 2009).fMRI gibi beyin görüntüleme sistemleri, insanlarda yapilan bu konudaki araştırmalara 1şık tutmuştur. Görsel yiyecek ipuçları ve yüksek enerji veren gıdaların tüketiminin madde kullanımıyla benzer şekilde insanlardaki ödüle ilişkin beyin yolaklarını etkilediği gösterilmiştir (Kenny, 2011). Bağımlılıkta sık görülen kullanmak için dayanılmaz istek hissetme, istenilenden daha fazla miktarda tüketme, madde kullanmak için fazla zaman harcamavb.davranışlarla örtüşü̆gü belirtilmektedir (Volkow \& O’Brien, 2007). Özellikle belirli yiyecek gruplarının madde bağımlılığında olduğu gibi beyindeki ödül sistemini etkilediğini gösteren çalışmalar mevcuttur (Hoebel, Rada, Mark \& Pothos, 1999; Nieto, Wilson, Cupo, Roques \& Noble, 2002). Dopamin hem yemekte hem de madde kullanımında da ödülün algılanma değeri ile ilişkili bulunmuştur. Madde ya da yiyeceğin ödül değeri ne kadar yüksek algılanırsa o kadar çok hücre dış1 dopamin salınımı olmaktadır (Volkow vd.,2002).Yiyecek tüketiminin yaşamın devamı için gerekli olduğu ve yeme sonrası doygunluğun yaygın bir durum olduğu göz önünde bulundurulduğunda, yeme bağımlılığının epidemiyolojisinin değerlendirilmesinin önemi ortaya çıkmaktadır. Bu çalışmada diyet polikliniğine çeşitli sebeplerle başvuran hastalarda yeme bağımlılığının epidemiyolojisinin araştırılması, ayrıca hangi besin gruplarına yönelik kontrolde zorlanıldığı vb. konuların incelenmesi amaçlanmıştır.

\section{Yöntem ve Gereç}

Çalışmaya basit tesadüfi örneklem yoluyla seçilen, Yalova Devlet Hastanesi Diyet Polikliniğine başvuran 101 kişi dahil edilmiştir. Haziran 2019-Ağustos 2019 tarihleri arasında gerçekleştirilen çalışmada, kişisel bilgi formu ve izin alınarak Türkçe geçerlilik ve güvenilirlik çalışması mevcut olan Yale Yeme Bağımlılığı ölçeğinden yararlanılmıştır(Bayraktar, 2012). Ölçeğin 2016 yılında geliştirilen 2.versiyonuna göre yeme bağımlılı̆̆ yaygınlığı daha yüksek görünse de ilk versiyonun hala kullanılabilir olduğu belirtilmektedir. Eski ve yeni madde kullanım bozukluğu kriterleri göz önünde bulundurularak ölçeğin ilk versiyonunun halen geçerli olduğu belirtilmektedir (Meule ve Gearhardta, 2014). Bu çalışmada da ölçeğin ilk versiyonu kullanılmıştır. Ölçeğin kesi değerleri dikkate alınarak kişilerin yeme bağımlılı̆̆ kriterlerini karşılayıp karşılamadığı değerlendirilmiştir. Araştırma bulguları değerlendirilirken istatistiksel metotlar(frekans, yüzde, ortalama, standart sapma) kullanılmıştır.

\section{Sonuçlar}

Katılımciların \%62,4'ü(n=63) kadın, \%37,6's1(n=38) erkekti. Yaş ortalaması 51,5( $\pm 14,77)$ idi. Yeme bağımlılı̆̆ görülme oranı \%60,4(n=61) olarak norm değer olan \%11,6'nın çok üzerinde bulundu. Katılımciların $\quad \% 64,4$ 'ü $(n=65) \quad$ tolerans, $\% 55,4(\mathrm{n}=56)$ klinik düzeyde işlev bozukluğu kriterini karşılamaktadır.

\section{Tartışma}

Bağımlılık multidisipliner bir alan olarak diyet polikliniklerinde de, yalnızca beslenme uzmanlarının değil bağımlılık uzmanlarının da işbirliğinde ele alınmalıdır. Ele alma sürecinde, madde bağımlılı̆g 1 tedavilerinde olduğu gibi, bağımlılı̆̆ın ortaya çıkmasında rol oynayan ruhsal nedenler saptanıp, bu ruhsal dürtülerle başa çıkma ve hayat boyu kontrol altına alma hedeflenmelidir. Ancak yeme bağımlılığ tedavisinin diğer madde bağımlılığı tedavilerinden farklılıkları olmak zorundadır. Diğer madde bağımlıları maddeyi tekrar kullanmadığı sürece arındırılmış kabul edilmektedir. Maddeyi tekrar kullanması durumunda bağımlı kabul edilir ama yeme bağımlılı̆g tedavisi birey hayat boyu yemek yemek zorunda olduğu için bu davranışın üzerinde kontrolü sağlamalıdır. Bu noktada tedavi sürecine yeme davranışını kontrol etme, beyin ödül sisteminin çalışma şekli vb. konulardaki psikoeğitimlerin dahil edilmesi önem arz etmektedir.

\section{Kaynaklar}

Ahmed, S. H., Guillem, K., \& Vandaele, Y. (2013). Sugar addiction: Pushing the drug-sugar analogy to the limit. Current Opinion in Clinical Nutrition and Metabolic Care, 16(4), 434439.
Avena, N. M., Rada, P., \& Hoebel, B. G. (2008). Evidence for sugar addiction: Behavioral and neurochemical effects of intermittent, excessive sugar intake. Neuroscience \& Biobehavioral Reviews, 32(1), 20-39. 
Bayraktar F, Erkman F, Kurtulus E.(2012). Adaptation study of Yale food addiction Scale. Klinik Psikofarmakol Bülteni22(1):S38.

Davis, C. (2013). From passive overeating to "food addiction": A spectrum of compulsion and severity. ISRN Obesity, 2013.

Gold, M. S., Frost-Pineda, K., \& Jacobs, W. S. (2003). Overeating, binge eating, and eating disorders as addictions. Psychiatric Annals, 33, 117-122.

Gold, M. S., Graham, N. A., Cocores, J. A., \& Nixon, S. J. (2009). Food addiction? Journal of Addiction Medicine, 3(1), 4245

Hoebel, B., Rada, P. V., Mark, G. P., \& Pothos, E. (1999). Neural systems for reinforcement and inhibition of behavior: relevance to eating, addiction and depression. Wellbeing: Foundations of Hedonic Psychology, 560-574.

Johnson, P. M., \& Kenny, P. J. (2010). Dopamine D2 receptors in addiction-like reward dysfunction and compulsive eating in obese rats. Nature Neuroscience, 13, 635-641.

Kenny, P.J.(2011). Reward mechanisms in obesity: New insights and future directions. Neuron, 69, 664-679.

Kelly, T., Yang, W., Chen, C.-S., Reynolds, K., \& He, J. (2008). Global burden of obesity in 2005 and projections to 2030. International Journal of Obesity, 32(9), 1431

Meule A., Gearhardt A.N. (2014). Food addiction in the light of DSM-5. Nutrients 6 (9), 3653-3671.

Meule, A. (2015). Focus: Addiction: Back by popular demand: A narrative review on the history of food addiction research. Yale Journal of Biology \& Medicine, 88(3), 295.
Mokdad, A. H., Marks, J. S., Stroup, D. F., \& Gerberding, J. L. (2004). Actual causes of death in the United States, 2000. Journal of the American Medical Association: The Journal of the American Medical Association, 291(10), 1238e1245.

Moreno C., Tandon R. (2011). Should overeating and obesity be classified as an addictive disorder in DS. Curr Pharm Des. 17, $1128-31$.

Ng, M., Fleming, T., Robinson, M., Thomson, B., Graetz, N., Margono, C., ... Abera, S. F. (2014). Global, regional, and national prevalence of overweight and obesity in children and adults during 1980e2013: A systematic analysis for the global burden of disease study 2013. The Lancet, 384(9945), 766-781.

Nieto, M., Wilson, J., Cupo, A., Roques, B. P., \& Noble, F. (2002). Chronic morphine treatment modulates the extracellular levels of endogenous enkephalins in rat brain structures involved in opiate dependence: a microdialysis study. Journal of Neuroscience, 22, 1034-1041.

Parylak, S. L., Koob, G. F., \& Zorrilla, E. P. (2011). The dark side of food addiction. Physiology \& Behavior, 104(1), 149e156

Volkow N.D., Fowler J.S., Wang G.J.G\& Goldstein R.Z (2002).Role of dopamine, the frontal cortex and memory circuits in drug addiction: insight from imaging studies. Neurobiol Learn Mem. Nov;78(3):610-24

Volkow, N. D., \& O’Brien, C. P. (2007). Issues for DSM-V: should obesity be included as a brain disorder? American Journal of Psychiatry, 164, 708-710.

Volkow, N. D., Wang, G. J., Tomasi, D., \& Baler, R. D. (2013). Obesity and addiction: Neurobiological overlaps. Obesity Reviews, 14, 2-18. 